\title{
Estimation of ventricular mass from the electrocardiogram
}

\author{
O. Visioli, G. Malagnino, C. Majorano, and A. Chiarini \\ From the Istituto di Clinica Medica Generale, Università di Parma, Parma, \\ and the Centro di Calcolo del CNEN, Bologna, Italy
}

In IOI cases post-mortem cardiac measurements were correlated with electrocardiographic parameters. Each of the 8 anatomical parameters examined gave significant regressions. The data concerning the left ventricle and the ratio between both ventricles were best represented, especially the per cent increase in left ventricular weight $(R=0.91 ; F=45.11 ; p<0.001)$. Less valid were the equations relating to the right ventricle. This study indicates that some anatomical cardiac features may be quantitatively determined from electrocardiographic data.

Previous investigators have attempted to establish whether the electrocardiogram gives a correct assessment of the presence or absence of ventricular hypertrophy (Selzer et al., 1958; Griep, 1959; Scott, 1960; Mazzoleni et al., 1964; Okamoto, Simonson, and Blackburn, 1965; Kilty and Lepeschkin, 1965; Romhilt and Estes, 1968; Liu and DeCristofaro, 1968; Gamboa, Klingeman, and Pipberger, 1969).

The purpose of our research was to determine whether electrocardiographic data can also give a quantitative estimate of ventricular mass. Indeed the statistical analysis revealed that all the ventricular anatomical parameters examined, whether normal or abnormal, could be quantitatively represented as a function of the electrocardiographic parameters.

\section{Subjects and methods}

Post-mortem measurements of the heart were performed in about 300 cases, and IOI cases were selected (Table I) for statistical analysis of the electrocardiograms. The reasons for case rejection included: (a) technically unsatisfactory electrocardiograms; (b) obvious cardiac necrosis or fibrosis; (c) complete bundle-branch block; (d) a large volume of pericardial fluid; and (e) obvious electrocardiographic repolarization abnormalities which were considered to be due to electrolyte imbalance or digitalis.

The electrocardiogram was taken at least a week before death. No previous selection was done as regards ventricular weight. The presence and degree of ventricular hypertrophy were evaluated on the basis of regression lines relating the weight of each ventricle with the height in normal subjects (Tardini et al., 1964).

Received 23 March 1970.
TABLE I General description of cases studied

\begin{tabular}{l} 
No. of cases ror $\left\{\begin{array}{l}M 73 \\
F \text { 28 }\end{array}\right.$ \\
Average age: 54.7 years \\
Fundamental cardiac disease \\
a) Hypertensive heart diseases: 59 cases \\
b) Chronic cor pulmonale $\quad: 25$ cases \\
c) Valvular heart diseases $\quad: 17$ cases \\
\hline
\end{tabular}

Ventricles exceeding the theoretical weight by at least Io per cent were considered as hypertrophic. The left and right ventricles were found to be hypertrophied in 70 and 83 cases, respectively, out of ror subjects examined. Thus in 52 subjects, the hypertrophy was present simultaneously in both ventricles. Conversely, in 4 cases both ventricles were normal.

The heart was extracted within 24 hours of death and examined according to the method previously described (Tardini et al., 1964). Separation and weighing of the two ventricles represent the crucial point of the method.

An IBM 7094/7040 computer was used for calculations. The statistical method was the 'stepwise' regression analysis based on a simple straight line model in which every variable appeared only on the first power. The BMD O2R programme was used. This programme computes a sequence of multiple linear regression equations in a stepwise manner. At each step one variable is added to the regression equation. The variable added is the one that makes the greatest reduction in the error sum of squares (Dixon, 1965). The programme also furnished the means, standard deviation, and the coefficient of correlation of all the variables.

Eight regressions were studied, the rule of 
TABLE 2 Anatomical parameters

\section{Anatomical parameters}

I) Left ventricular weight (LVW)

2) Percentage changes in left ventricular weight in comparison with theoretical values* (PILV)

3) Percentage of left ventricle upon total cardiac weight (PLV)

4) Right ventricular weight (RVW)

5) Percentage changes of right ventricle weight in comparison with theoretical values* (PIRV)

6) Percentage of right ventricular upon total cardiac weight (PRV)

7) The ratio between parameters I and 4 (LVW/RVW)

8) The ratio between parameters 2 and 5 (PILV/PIRV)

Electrocardiographic parameters

XI Mean electrical axis of QRS in the frontal plane (ÂQRS)

$\mathrm{X}_{2}$ Axis of the terminal $0.04 \mathrm{sec}$. vector in frontal plane

$X_{3}$ Mean electrical axis of $T$ wave in the frontal plane (ÂT)

$\mathrm{X}_{4}$ Angular difference ÂQRS-ÂT

X5 Angular difference between initial and terminal $0.04 \mathrm{sec}$. axis vectors

X6 Ventricular activation time (intrinsicoid deflection) in $\mathrm{VI}-2$

$\mathrm{X}_{7}$ Ventricular activation time (intrinsicoid deflection) in $\mathrm{V}_{5}-6$

X8 Duration of QRS in VI-2

$\mathrm{X}_{9}$ Duration of QRS in $\mathrm{V}_{5}-6$

XIO $R / S$ amplitude ratio in lead I (LI)

XII $R$ amplitude in $\mathrm{LI}+\mathrm{S}$ amplitude in $\mathrm{L}$

$\mathrm{X}_{12} \mathrm{Q}$ wave amplitude in aVR

$X_{13} R$ wave amplitude in aVR

XI4 $Q / R$ amplitude ratio in aVR

XI5 $R$ wave amplitude in aVL

- XI6 R/S amplitude ratio in aVL

- XI7 $R$ wave amplitude in aVF

XI8 Amplitude of maximal negative deflection in aVR plus amplitude of maximal positive deflection in aVL

Xr9 Lewis index

$X_{20}$ Jinich index

- X2I $S$ wave amplitude in $V_{I}$

$X_{22} R / S$ amplitude ratio in VI

- $\mathbf{X}_{23} \mathbf{R}$ wave amplitude in $\mathrm{V}_{5}$

$X_{24} S$ wave amplitude in $V_{5}$

2. X25 R/S amplitude ratio in V5

$\mathrm{X}_{26} \mathrm{R} /(\mathrm{R}+\mathrm{S})$ amplitude ratio in $\mathrm{V}_{5}$

- $\mathrm{X}_{27}(\mathrm{R} / \mathrm{SVI}) /(\mathrm{R} / \mathrm{SV} 5)$

$\mathrm{X} 28 \mathrm{R}$ wave amplitude in V6

X29 I Sokolow-Lyon index

$\mathrm{X}_{30}$ II Sokolow-Lyon index

$\mathrm{X}_{31}$ Blondeau index

- X32 Mori index

$\mathrm{X}_{33}$ Combined index (X29 minus $\left.\mathrm{X}_{30}\right) \dagger$ $\rightarrow$

- Extracardiac parameters

- $x_{34}$ Sex

X35 Age

X36 Body weight

$\mathrm{X}_{37}$ Per cent variation of body weight from the normals

Xै. Emphysemag choice for selecting the variables was that of adding new variables until Snedecor's $F \geqslant I$, in order to reduce the systematic errors that would be obtained with a strictly 5 per cent probability level.

The interrelations between the two sets of measurements (anatomical and electrocardiographic) were studied by canonical-correlation methods. This canonical correlation represents the maximum correlation between linear functions of the two sets of variables. The MSA 'Supercanon' programme was used (Jones, 1964). This also provided coefficients of multiple correlation of each electrocardiographic variable as compared to all the anatomical variables together.

\section{Results}

Clinical data are presented in Table I. Table 2 lists the anatomical measurements which were correlated with the indicated electrocardiographic data and extracardiac factors. The canonical correlation gave a highly significant result $\left(R=0.98 ; \chi^{2}=586.42 ; p<0.84 \times 10^{-25}\right)$.

Table 3 shows the equations of regression with the respective coefficients of correlation, the Snedecor's F test, the degree of freedom (d.f.), and the multiple correlation coefficients (R). All the regressions were significant. The anatomical parameters of the left ventricle and the ratio of both ventricles gave higher correlations than the right ventricle. The parameter best represented by multiple regressions was the percentage changes of left ventricle weight in comparison with theoretical values $(\mathrm{R}=0.91 ; \mathrm{F}=45.1 \mathrm{I} ; \mathrm{p}<0.00 \mathrm{I})$. In contrast the percentage changes of right ventricular weight resulted in the lowest $F$ test $(F=4 \cdot 20)$. The right ventricular parameter in which the surface of regression is best represented from experimental data was the percentage of right ventricle upon total cardiac weight. The left ventricular weight was represented by a large number (18) of variables, which suggests that many more electrocardiographic findings independently represent this anatomical feature.

In Table 4 the values of the $F$ test of the electrocardiogram that comprise the regression surface are indicated. The numerical values of the $F$ test do not give a precise quantitative evaluation of the importance of

* As described in the test, the normal weights are calculated using straight line of regression based on height of subject according to Tardini and co-workers (I964). + See Visioli et al. (1964).

$\ddagger$ The value $I$ was allowed to men and the value $o$ to women.

$\int$ Normal body weight as indicated in Build and Blood Pressure Study, Vol. I, Society of Actuaries, Chicago, 1959.

I The extent and importance of emphysema are quoted from $I$ to 4 . 
TABLE 3 Regressions for 8 anatomical parameters, $F$ values, degree of freedom (d.f.) and significance $(p)$ of regressions are also indicated, together with correlation coefficients $(R)$ of single anatomical parameters with all electrocardiographic and extracardiac parameters that enter in respective regressions

\begin{tabular}{|c|c|c|c|c|c|}
\hline Anatomical parameters & Regressions & $F$ & $\begin{array}{l}\text { d.f. } \\
n I / n 2\end{array}$ & $p$ & $R$ \\
\hline Left ventricular weight & $\begin{array}{l}82.2+1.53 \times 10^{-1} X_{3}-1.59 \times 10^{-1} X_{5}+6.96 X 6- \\
\quad-4.43 X_{9}+3.76 X_{12}+7.31 X_{13}-6.65 X_{17}+ \\
+3.64 X_{21}-7.69 \times 10^{-1} X_{22}-4.42 X_{23}+ \\
+2.22 \times 10^{-1} X_{25}+4.12 X_{28}-1.98 X_{29}+ \\
+2.74 X_{32}+28.5 X_{34}-0.57 \times 35+1.81 X_{36}- \\
1 \cdot 07 X_{37}\end{array}$ & $8 \cdot 4 I$ & $18 / 82$ & $<0.001$ & 0.81 \\
\hline $\begin{array}{l}\text { Percentage change of left } \\
\text { ventricular weight in } \\
\text { comparison with } \\
\text { theoretical values }\end{array}$ & $\begin{array}{l}-5 \cdot 7 \mathrm{I}-\mathrm{I} \cdot 95 \times 10^{-1} X_{10}+\mathrm{I} \cdot 53 X_{11}-4 \cdot 78 X_{23}+ \\
\quad+\mathrm{I} \cdot 75 X_{24}+2 \cdot 54 X_{28}-0.93 X_{29}-\mathrm{I} \cdot 13 X_{31}+ \\
\quad+\mathrm{I} \cdot 6 \mathrm{I} X_{32}+3 \cdot 78 X_{33}+2 \mathrm{I} \cdot 75 X_{34}\end{array}$ & $45 \cdot$ II & $10 / 90$ & $<0.001$ & 0.91 \\
\hline $\begin{array}{l}\text { Percentage of left ventri- } \\
\text { cular upon total cardiac } \\
\text { weight }\end{array}$ & $\begin{array}{l}31 \cdot 1-7.02 \times 10^{-1} X_{17}+1 \cdot 37 \times 10^{-1} X_{19}+ \\
\quad+3.14 \times 10^{-1} X_{21}+11 \cdot 7 X_{26}+9.69 \times 10^{-2} X_{31} \\
\quad-1 \cdot 36 \times 10^{-1} X_{35}+1.09 \times 10^{-1} X_{36}-1.53 \times \\
\quad \times 10^{-1} X_{37}\end{array}$ & $19 \cdot 21$ & $8: 92$ & $<0.001$ & 0.79 \\
\hline Right ventricular weight & $\begin{array}{l}92 \cdot 6+6.62 \times 10^{-2} X_{2}+8.41 \times 10^{-2} X_{4}-2 \cdot 84 X 9+ \\
\quad+5.56 X_{13}+\mathrm{I} \cdot 44 X_{21}+1 \cdot 2 \mathrm{I} X_{23}-\mathrm{I} \cdot 65 X_{33}+ \\
\quad+26 X_{34}+5.35 \times 10^{-1} X_{36}\end{array}$ & $4 \cdot 86$ & 9/9I & $<0.01$ & 0.57 \\
\hline $\begin{array}{l}\text { Percentage changes of left } \\
\text { ventricular weight in } \\
\text { comparison with } \\
\text { theoretical values }\end{array}$ & $\begin{array}{l}63.7+6.02 \times 10^{-2} X_{2}+1.35 \times 10^{-1} X_{4}+ \\
\quad+5.58 X_{13}-29.4 X_{26}-0.99 X_{28}\end{array}$ & $4 \cdot 70$ & $5 / 95$ & $<0.01$ & 0.45 \\
\hline $\begin{array}{l}\text { Percentage of right ven- } \\
\text { tricular upon total } \\
\text { cardiac weight }\end{array}$ & $\begin{array}{l}25 \cdot 35-\mathrm{r} \cdot 8 \mathrm{I} \times 10^{-2} \mathrm{X}_{4}+\mathrm{I} \cdot 84 \times 10^{-2} \mathrm{X}_{5}- \\
\quad-\mathrm{I} \cdot 06 \mathrm{X6}+8 \cdot 16 \times 10^{-1} \mathrm{XI}_{3}+\mathrm{I} \cdot 42 \times 10^{-1} \mathrm{X}_{22-} \\
\quad-2 \times 10^{-2} \mathrm{X} 25\end{array}$ & 7.99 & II $/ 89$ & $<0.001$ & 0.70 \\
\hline $\begin{array}{l}\text { Ratio between two } \\
\text { ventricular weights }\end{array}$ & $\begin{array}{l}\mathrm{I} \cdot 34+1.72 \times 10^{-3} X_{3}-2.74 \times 10^{-3} X_{4}+ \\
+8.99 \times 10^{-2} X 6-1.93 \times 10^{-2} X 18+3.41 \times 10^{2} \\
X 19-1.25 \times 10^{-2} X 20-4.51 \times 10^{-2} X 23+6.19 \\
\quad \times 10^{-2} X 28-1.92 \times 10^{-2} X 29+4.03 \times 10^{-2} X 33\end{array}$ & 13.41 & $10 / 90$ & $<0.001$ & 0.77 \\
\hline $\begin{array}{l}\text { Ratio between two ven- } \\
\text { tricular weight percen- } \\
\text { tage changes }\end{array}$ & $\begin{array}{l}\mathrm{I} \cdot 05+0.98 \times 10^{-3} X_{3}-\mathrm{I} \cdot 40 \times 10^{-3} X_{4}-2.6 \mathrm{I} \times \\
\times 10^{-2} X 17+\mathrm{I} \cdot 93 \times 10^{-2} X 19-8.02 \times 10^{-3} \\
X 20-9.23 \times 10^{-3} X 23+1.44 \times 10^{-3} X 25+ \\
+3.23 \times 10^{-1} X 26-5.88 \times 10^{-3} X_{31}-5.80 \times \\
\quad \times 10^{-3} X_{35}\end{array}$ & $7 \cdot 63$ & $10 / 90$ & $<0.001$ & 0.68 \\
\hline
\end{tabular}

each electrocardiographic parameter, because the rule of choice that limits the number of variables may influence their values. However, a high value suggests a relative importance of that electrocardiographic parameter.

Table 4 confirms that only the electrocardiographic indices which are commonly used in the diagnosis of ventricular hypertrophy appear to have a high $F$ value. An exception to this is the second Sokolow index which does not appear in the regression of right ventricular weight. Indexes that strongly reduce the variance of each anatomical parameter are listed in decreasing order of statistical significance.

I Left ventricular weight: $R$ wave amplitude in aVF; Mori index; $\mathrm{R}$ wave amplitude in $\mathrm{V}_{5}$; $\mathrm{R} / \mathrm{S}$ amplitude ratio in $\mathrm{V}_{5}$.

2 Percentage changes of left ventricular weight: combined index (the regression calculated with this index alone gave a strong dependence reducing greatly the majority of the variance: $F=227 ; I ; 99$ d.f.; $r=0.83) ; R$ wave amplitude in V5.

3 Percentage of left ventricular weight: $R /(R+S)$ amplitude ratio in $V_{5} ; R$ wave amplitude in aVF; $S$ wave amplitude in VI. 4 Right ventricular weight: combined index. 5 Percentage changes of right ventricular weight: no distinction exists between the electrocardiographic indexes; the regression is far from the experimental data, even if the $F$ test is significant. 
6 Percentage of right ventricular weight: $R$ wave amplitude in aVF; $R$ wave amplitude in $\mathrm{V}_{5}$ and V6; R/S amplitude ratio in VI.

7 The ratio between anatomical parameters $I$ and 4: Combined index; Lewis index; $R$ wave amplitude in $\mathrm{V}_{6}$ and $\mathrm{V}_{5}$; angular difference $\hat{A} Q R S-\hat{A} T$. Even in this regression the combined index greatly reduces the variance of the anatomical parameter.

8 The ratio between anatomical parameters 2 and 5: Lewis index.

Regarding the extracardiac data, sex is important in calculating the regression of left ventricular weight, percentage increase of left ventricular weight, and right ventricular weight, but in calculating the regression of the percentage of left ventricle upon total cardiac weight, age is a determinant factor. Emphysema does not appear in any regression. All extracardiac parameters especially influence the evaluation of the left ventricular weight.

\section{Discussion}

These results indicate that (a) the electrocardiogram has been shown to represent many anatomical parameters; (b) regarding diagnosis, each anatomical measurement may be represented as a function of many electrocardiographic parameters. The anatomical data that most significantly influenced the electrocardiogram are those relative to the left ventricle (absolute weight and especially increase in weight). Next in importance was the ratio between the two ventricles. It appears that the electrocardiogram gave scanty information concerning the weight of the right ventricle and increase in its weight; however, the percentage of the cardiac weight that is right ventricular was more closely approximated.

- In determining the multiple regressions of the single anatomical parameters the praecordial electrocardiographic data were the most important. This was particularly true of the combined index proposed by us (Visioli et al., 1964).

Of the extracardiac parameters surprisingly - enough only emphysema was not entered. Emphysema was graded I-4, but it was - present only in patients with cor pulmonale and in these cases it was always 3 or 4 .

A The proposed model has obvious limitations due to the limited number and selection of cases examined. These limitations might be -overcome by the study of a larger number of cases. On the other hand, expanding the number of cases would probably introduce
TABLE $4 \quad F$ test values of electrocardiogram and extracardiac variables that enter in regressions for anatomical parameters

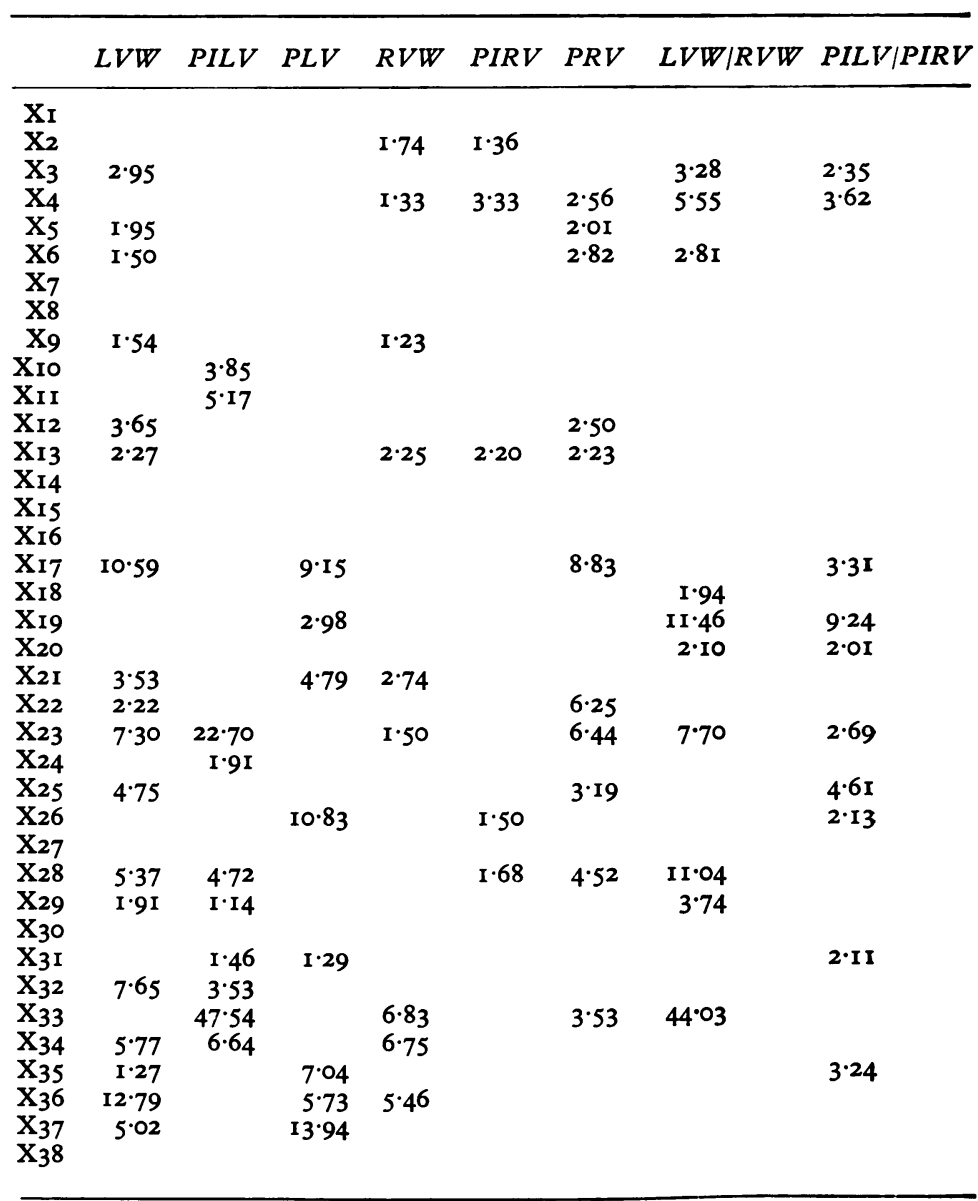

heterogeneous factors. However, using a clustering method of analysis, the problem of heterogeneity can be solved, and for each homogeneous group the equations of regression could be calculated.

In our opinion such data should be obtained by gathering cases from many centres. Such efforts may eventually improve the design of automated systems for electrocardiographic analysis and provide not only a general diagnosis of presence or lack of ventricular hypertrophy, but also some clinically useful quantitative information about weight and degree of hypertrophy of both ventricles.

The authors wish to thank L. Vitali Mazza, M.D., and P. Anversa, M.D., of the Institute of Pathology, Parma University, for their help in collecting the anatomical data. 


\section{References}

Dixon, W. J. (1965). BMD - Biomedical Computer Programs. University of California, Los Angeles.

Gamboa, R., Klingeman, J. D., and Pipberger, H. V. (I969). Computer diagnosis of biventricular hypertrophy from the orthogonal electrocardiogram. Circulation, 39, 72.

Griep, A. H. (I959). Pitfalls in the electrocardiographic diagnosis of left ventricular hypertrophy: a correlative study of 200 autopsied patients. Circulation, 20, 30.

Jones, K. J. (1964). MSA - Multivariate Statistical Analysis. Harvard University Press.

Kilty, S. E., and Lepeschkin, E. (1965). Effect of body build on the QRS voltage of the electrocardiogram in normal men. Its significance in the diagnosis of left ventricular hypertrophy. Circulation, 3I, 77.

Liu, C. K., and DeCristofaro, D. (1968). Sensitivity and specificity of electrocardiographic evaluation of LVH in 364 unselected autopsy cases. American Heart fournal, 76, 596.

Mazzoleni, A., Wolff, R., Wolff, L., and Reiner, L. (1964). Correlation between component cardiac weights and electrocardiographic patterns in 185 cases. Circulation, 30, 808.
Okamoto, N., Simonson, E., and Blackburn, H. (1965) $T$ he $T-V_{1}>T-V_{6}$ pattern for electrocardiographic diagnosis of left ventricular hypertrophy and ischemia. Sensitivity and specificity. Circulation, 31, 719.

Romhilt, D. W., and Estes, E. H. (1968). A pointscore system for the ECG diagnosis of left ventricular hypertrophy. American Heart fournal, 75, 752.

Scott, R. C. (1960). The correlation between the electrocardiographic patterns of ventricular hypertrophy and the anatomic findings. Circulation, 21, 256.

Selzer, A., Ebnother, C. L., Packard, P., Stone, A. O., and Quinn, J. E. (1958). Reliability of electrocardiographic diagnosis of left ventricular hypertrophy. Circulation, 17, 255.

Tardini, A., Visioli, O., Fietta, M., Donelli, R., and Barbaresi, F. (1964). Basi anatomiche per lo studio delle correlazioni anatomo-elettrocardiografiche nell'ipertrofia ventricolare. Rivista di Anatomia Patologica e di Oncologia, 25, I.

Visioli, O., Barbaresi, F., Chizzola, A., Donelli, R., and Fietta, M. (1964). Studio correlativo fra parametri anatomici e misure elettrocardiografiche nell'ipertrofia cardiaca. Giornale di Clinica Medica, 45, 1267. 